\section{Help your patients brush interdentally with ease}

Sometimes, those hard-to-reach areas feel like too much effort to tackle properly, especially for patients whose lifestyles are busy.

You could make their lives easier by suggesting they use the TANDEX WOODI - the interdental tool that effectively reduces the build-up of plaque between the teeth. In addition, the brush is easy to hold and comfortable to use, so those hard-to-reach areas will be taken care of.

For an interdental brush that cleans the tooth surfaces and massages the gums, start recommending the TANDEX WOODI today.

For more information on Tandex, visit https://tandex.dk/ or the Facebook page https://www.facebook.com/TandexUK.

Tandex products are now available from CTS Dental Supplies https://www.cts-dental.com/ and DHB Oral Healthcare https://dhb.co.uk/.

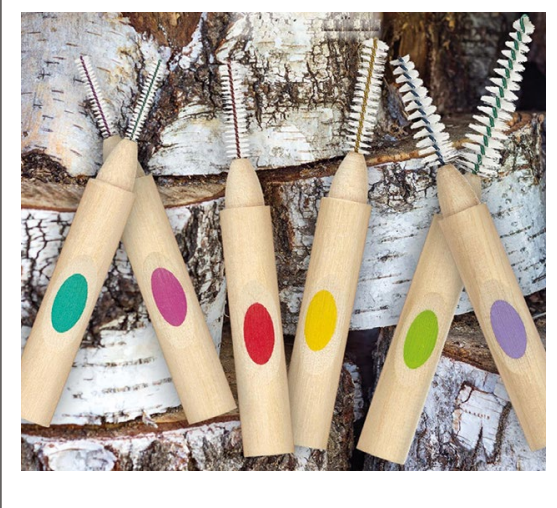

\title{
Could your patients benefit from Biosmalto?
}

The Biosmalto Impact Action Mousse utilises an innovative formulation to deliver rapid remineralisation benefits, while protecting the teeth from further damage through acid

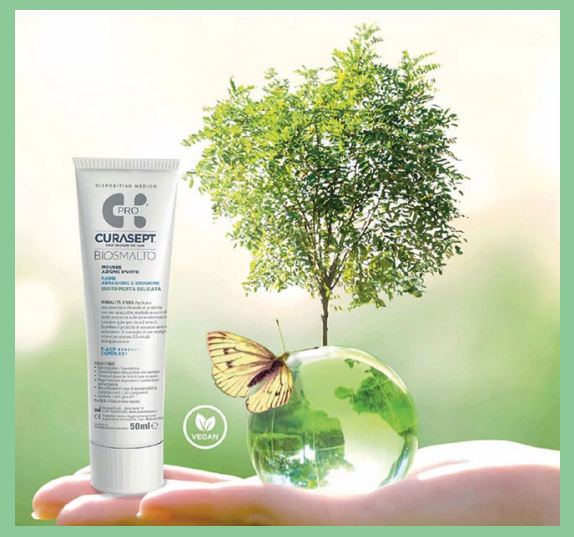

erosion, acid attacks, mechanical abrasion and sensitivity. It can be used as part of therapy to treat carious lesions, tooth wear, dry mouth, white spots, molar or incisor demineralisation, fluorosis or sensitivity (especially pre- and post-air polishing).

The chairside application of Biosmalto provides an additional service for patients, with a $50 \mathrm{ml}$ tube available for patients to take home. SLS-free, easy to apply, vegan and translucent, it is also suitable for patients with lactose intolerance and can be used with or without trays.

For more information on the industryleading products available from J\&S Davis, visit www.js-davis.co.uk, call 01438747344 or email jsdsales@js-davis.co.uk.

\section{Get the support you and your patients deserve!}

Concerned about doing the right thing by your patients? Ensure that they are always treated to the highest ethical standard by training with IAS Academy.

A global community of world-class teachers and colleagues have come together with one common goal: to empower dentists to treat their patients confidently with the best and most ethical treatments available.

Tooth preservation dentistry is at the core of their ethos which means you will learn how to preserve your patients' teeth in delivering a final and lasting treatment. The support you will receive will be continuous so if you're faced with an ethical dilemma once a course is completed, you can still turn to IAS Academy for help and reassurance.

For more information on upcoming IAS Academy training courses visit www. iasortho.com or call 01932336470 (Press 1).

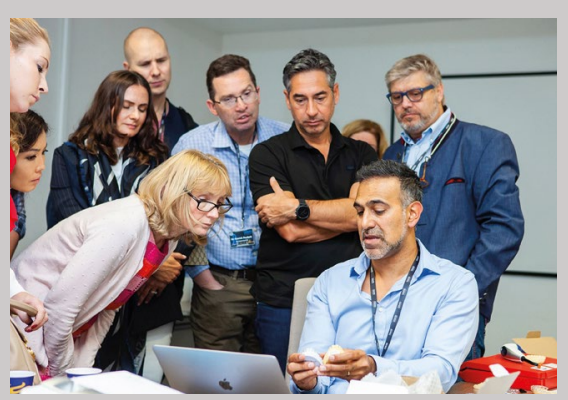

\section{Cosmetic waste disposal done right}

More and more dentists are inching their way into the world of cosmetics, which means they'll be able to offer a more comprehensive range of treatments to patients - in a safe and sterile environment.

Introducing non-surgical cosmetic treatments, such as botulinum toxin injections, means dentists need an appropriate disposal system for any cytostatic waste (the purple waste stream on The Department of Health's colour coded guide to best practice waste disposal). Initial Medical provides a range of waste disposal solutions, such as innovative colour-coded sharps bins.

For needles used to administer botulinum toxin injections, dentists will need the purple coded sharps bin - they are available in sizes from 0.4 litres to 35 litres and are designed to fit seamlessly into your dental practice. They even include mounting brackets to place the sharps bin in the most optimal position. For needles used to administer anaesthetic, professionals will need one of our yellow colour-coded sharps bins. Giving your patients more choice doesn't have to mean more confusion - with Initial Medical's colour-coded sharps bins, keeping patients and staff protected is as easy as ever.

For further information visit www.initial. co.uk/medical or call 08708504045 .

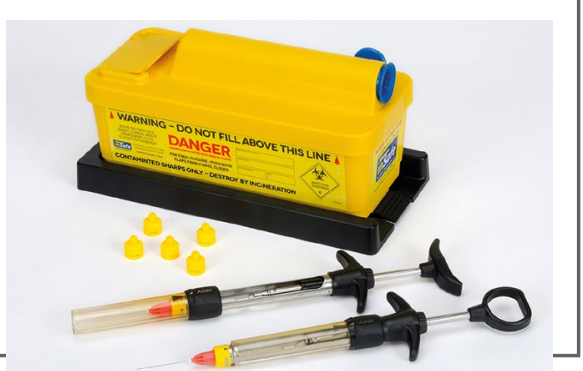

